\title{
Gamma Knife Radiosurgery in Pituitary Adenomas
}

\author{
a report by \\ Frederic Castinetti, ${ }^{1}$ Jean Regis ${ }^{2}$ and Thierry Brue ${ }^{3}$
}

1. Physician, Department of Endocrinology; 2. Professor of Neurosurgery, Department of Functional Neurosurgery;

3. Professor of Endocrinology, and Head, Department of Endocrinology, Timone University Hospital, Mediterranean University of Marseille

DOI:10.17925/EE.2008.04.00.60

Pituitary adenomas are benign tumours that may induce clinical signs either by secreting hormones (growth hormone [GH], adrenocorticotropin hormone $[\mathrm{ACTH}]$ or prolactin [PRL]) or by local mass effect, particularly chiasmatic compression. Thus, the therapeutic algorithm is different whether the aim of the treatment is to control signs of hormone hypersecretion (for instance in a secreting microadenoma) or tumour volume (for instance in a large non-secreting pituitary adenoma). Trans-sphenoidal surgery is the treatment of choice for most pituitary adenomas; however, this surgical approach does not always allow definite remission and efficacious adjunctive treatment is often needed. Medical treatments have an inconstant effectiveness, and conventional radiotherapy, although highly effective, induces high rates of panhypopituitarism. ${ }^{1-4}$

Gamma knife (GK) radiosurgery is a neurosurgical technique using a source of cobalt-60. In a single session narrow beams are delivered with stereotactic precision and accuracy in order to destroy or biologically modify a target without opening the skull and with minimal damage to the surrounding brain. The critical structures around the target are spared through the high conformity and anatomical selectivity of dose delivery. In contrast to radiotherapy, which covers the lesion and the surrounding structure with a fractionated dose, stereotactic radiosurgery aims to minimise injury to the surrounding structures included in the field of irradiation by fractionation, creating a gradient of toxicity on the target cells and the normal tissue (biological selectivity). Moreover, the radiobiological effect of a single high dose is theoretically higher than a fractionated treatment for benign slowly growing lesions such as pituitary adenomas. ${ }^{5-7}$ Several studies have been published on the efficacy of GK radiosurgery in secreting adenomas (acromegaly, Cushing's disease and

Frederic Castinetti is a physician in the Department of Endocrinology at the Timone University Hospital at the Mediterranean University of Marseille. His main clinical interests are pituitary ontogenesis and tumorigenesis. His research activities include clinical research in pituitary adenomas and in pituitary transcription factors involved in combined pituitary hormone deficiencies.

Jean Regis is a Professor of Neurosurgery in the Department of Functional Neurosurgery at the Timone University Hospital, Mediterranean University of Marseille. He is the Medical Co-ordinator of Gamma Knife radiosurgery in Marseille. His primary clinical and research interests are brain tumours, pituitary tumours and epilepsy. Professor Regis has coauthored more than 85 peer-reviewed articles referenced in PUBMED.

Thierry Brue is a Professor of Endocrinology and Head of the Department of Endocrinology at the Timone University Hospital at the Mediterranean University of Marseille, and Medical Co-ordinator of the Rare Disease Reference Centre for Pituitary Deficiency. His main clinical interests are in neuroendocrinology. His research activities include clinical research in pituitary disorders and co-ordination of a clinical research network on genetically determined pituitary hormone deficiency. Professor Brue has co-authored more than 85 peer-reviewed articles referenced in PUBMED.

E: thierry.brue@mail.ap-hm.fr prolactinomas) and non-secreting pituitary adenomas. The aim of radiosurgery is different whether the adenoma is a secreting one or not, as it will also have to reduce excess hormone secretion in the first case. Based on the literature and our own data, this article will attempt to determine the efficacy, adverse effects and role of GK radiosurgery in the therapeutic algorithm of pituitary adenomas.

\section{Antisecretory Effects of Gamma Knife Radiosurgery}

\section{Gamma Knife Radiosurgery and}

\section{Growth-hormone-secreting Pituitary Adenomas}

First-line treatment of acromegaly is trans-sphenoidal surgery, ${ }^{2}$ but the remission rate ranges from 44 to $74 \%$, varying with the neurosurgeon's experience, the size of the adenoma (micro- or macroadenoma) and pre-surgical GH levels. In other cases surgery is contraindicated or impossible, due to cavernous invasion, for instance..$^{8-11}$ Currently published studies reported a wide ranging efficacy of GK radiosurgery, varying from 17 to $100 \% .12-24$ This range was probably due to various criteria of remission because only a few studies to date have used the most recent criteria, and the efficacy of GK radiosurgery is probably about $40-50 \% .{ }^{20-23}$ Our study reported only $17 \%$ of patients in remission, but $23 \%$ of our patients were controlled by somatostatin agonists even though this was not the case with the same treatment before GK radiosurgery. Withdrawal of this treatment would probably have increased our remission rate, as these patients were considered uncured at the end of the study. ${ }^{20}$ Our team and others have shown similar efficacy whether GK radiosurgery was used as a primary treatment (without surgery) or as an adjunctive treatment (after unsuccessful surgery), suggesting that GK radiosurgery could be proposed as an alternative first-line treatment in case of contraindications to surgery. ${ }^{20-22}$ One of the main drawbacks of the technique, discussed below, is the delay in time to remission: with a mean time to remission varying from 12 to 60 months in the literature, an adjunctive treatment - e.g. somatostatin agonists or pegvisomant - is required during this period to control excess secretion. 6,7,20-23,25

Predictive factors of remission vary among the studies, and include dose to the target, initial GH and insulin-like growth factor 1 (IGF-1) levels and target volume as possible valuable predictive factors, but their impact on the final result was not systematically reported in the literature. The radioprotective effect of somatostatin agonists given at the time of radiosurgery remains a matter of controversy. This is because the initial hypothesis that somatostatin agonists could reduce the proliferation rate of the adenoma ${ }^{24}$ and then decrease the efficacy of radiosurgery was not confirmed by two of the three recent studies on the topic, and was not evaluated in one.20-23 However, we share the viewpoint of other investigators that this treatment should be stopped shortly before GK, as initial GH and IGF-1 levels could be predictive factors of remission. 


\section{Gamma Knife Radiosurgery, Adrenocorticotropic Hormone-secreting Pituitary Adenomas and \\ Cushing's Disease}

First-line treatment of Cushing's disease is trans-sphenoidal surgery. ${ }^{4}$ Remission rate ranges from 50 to $80 \%$, varying with the type of adenoma and the experience of the neurosurgeon. ${ }^{26-30}$ Recent data in the literature reported an elevated risk of recurrence ( $>25 \%$ ) when prolonged postsurgical follow-ups were performed ( $>5$ years). ${ }^{31}$

Only a few studies reported the experience of GK radiosurgery in Cushing's disease: the remission rate ranges from 10 to $83 \%{ }^{15,32-37}$ However, the more elevated rates of remission were observed in radiosurgical series from the pre-magnetic resonance imaging (MRI) era, involving elevated rates of induced hypopituitarism (two-thirds of treated patients presented at least one new anterior pituitary deficiency at last follow-up). ${ }^{32}$ The GK rate of remission is probably closer to $40-50 \%$ of cases, as described in our study. ${ }^{37}$ As observed for acromegaly, GK radiosurgery seemed equally effective as an adjunctive or as a primary treatment. Again, the main drawback of the technique is the delay to remission, estimated to be 24-36 months, requiring efficacious medical treatment during this period to control excess cortisol signs, 6,25,37 which may prove challenging.

Predictive factors of remission varied with studies; however, dose and target volume seemed valuable predictive factors. Interestingly, we found that the subgroup of patients treated with ketoconazole at the time of radiosurgery had a lower rate of remission than the untreated subgroup; ${ }^{37}$ however, physiopathological explanation of this mechanism remains unclear, even if in vitro data reported ACTH decreasing with ketoconazole infusion, suggesting a central effect of the drug (in addition to its well-known peripheral adrenal effects). ${ }^{38}$ None of the studies published to date reported an effect of pre-GK hormonal levels on the final result of the procedure.

\section{Gamma Knife Radiosurgery and Prolactin-secreting Pituitary Adenoma}

First-line treatment of PRL hypersecretion depends on the type of adenoma: dopamine agonists may be proposed, or - less frequently surgery in cases of macroadenoma. Medical or surgical remission was reported in about $90 \%$ of microprolactinomas, and surgical remission rates do not exceed $50 \%$ in macroprolactinomas. However, dopamine agonists are sometimes not tolerated, and in cases of unsuccessful or contraindicated surgery an adjunctive treatment may be proposed. ${ }^{1}$

GK remission rates range from 20 to $80 \%$ (mean 50\%) after a mean period of about 30 months. 13,15,16,19,34,39-44 Predictive factors include dose to the target and target volume. No study published to date has reported the influence on the final result of the procedure of a low PRL level before GK. However, due to the effective medical and surgical treatments, published studies were always based on small numbers of patients. Only one series reported GK treatment in 128 patients, but the low rate of remission (15\%) could suggest that a large number of patients in this series did not represent the ideal indication for GK as they were systematically primarily treated with GK. ${ }^{42}$ It is important to stress that, as in acromegaly, a few studies reported a presumably radioprotective effect of dopamine agonists in that patients treated at the time of radiosurgery were less frequently cured than the ones who were not treated; however, this may be due to a selection bias and, therefore, withdrawal of dopamine agonists before GK may be advocated. ${ }^{41,45}$

\section{Antitumoral Effects of Gamma Knife Radiosurgery}

The decrease in volume was reported to range between 70 and 100\% in cases of pituitary adenomas, $6,25,46$ varying with the dose to the tumour and cavernous sinus invasion. ${ }^{46}$ One study described a transient increase in the days following GK, probably due to an inflammatory oedema of the target. ${ }^{23}$ These results are of importance, especially in non-secreting adenomas in which the main objective of the procedure is to control tumour size. A recent study reported the outcome of 62 patients treated by GK for non-functioning pituitary adenomas, with a median follow-up of 64 months: only two patients presented re-growth of the tumour after the radiosurgical procedure, whereas tumour size decreased in $60 \%$ and

The fact that all patients in this study had been previously treated by surgery confirms that gamma knife could be a valuable adjuvant treatment in cases of incomplete surgical resection of nonfunctioning pituitary adenoma.

remained unchanged in $37 \%$ of cases. The fact that all patients in this study had been previously treated by surgery confirms that GK could be a valuable adjuvant treatment in cases of incomplete surgical resection of non-functioning pituitary adenoma. ${ }^{47}$

\section{Adverse Effects of Gamma Knife Radiosurgery}

\section{The Risk of Hypopituitarism}

Rates of GK-induced hypopituitarism range from 0 to $66 \%$, varying with the dose (dose to the stalk in one study), accuracy in target definition (one study reported $66 \%$ hypopituitarism in the pre-MRI era of GK) and pre-GK radiotherapy or radiosurgery (which increases the risk of hypopituitarism). $6,7,20,25,37,48$ However, most published studies were based on short-term follow-up, and prolonged studies are needed to confirm this relatively low incidence of hypopituitarism. The risk of hypopituitarism increases with the period after radiosurgery, and increased rates of remission are usually associated with increased rates of hypopituitarism. The need for a precise target is evident, as totosellar radiosurgery will induce panhypopituitarism in the majority of cases.

\section{Optic-nerve Neuropathy}

The rate of GK-induced optic neuropathy is estimated to be less than $2 \%$ of cases. The risk increases if the target-chiasm distance is $<5 \mathrm{~mm}$ and if the dose to the chiasm is $>8-10$ Gy. $21,49-51$ Therefore, it is currently not recommended to perform GK if the target is too close to the optic chiasm.

\section{Other Potential Adverse Effects}

GK radiosurgery can induce transient headaches in the days following the procedure.7,25 Other severe side effects including radiation-induced tumours or cognitive dysfunctions were not reported. However, mean follow-up of currently published studies is too short to draw any firm conclusions on these adverse effects previously described after conventional radiotherapy. Therefore, it is hard to determine how safe 
GK is, or if longer follow-up studies will describe new side effects. Further studies are needed to better determine the long-term effects of such a procedure.

\section{A Comparison with Conventional Radiotherapy}

The efficacy of conventional radiotherapy in controlling hormone hypersecretion is estimated to be about $50-90 \%$ of cases, whatever the type of secretion. ${ }^{52-57}$ However, conventional radiotherapy has two main drawbacks: the first is the time to remission - equal to five to 10 years - which requires effective medical treatment during this period. The second is the elevated risk of side effects, including hypopituitarism (in more than $80 \%$ of cases), ${ }^{52-57}$ optic neuritis, radiation-induced cerebral tumours, cerebral infraction and cognitive dysfunctions. ${ }^{16,58-61}$ Cognitive dysfunctions occurred after a mean period of 10-20 years and were not described with the use of GK; however, studies based on GK had a shorter time to follow-up and prolonged studies will be necessary to confirm this point. In nonfunctioning pituitary adenomas, results of conventional radiotherapy are comparable to those of GK, with unchanged or decreased tumour volume in the majority of cases.

Comparisons between radiosurgery and radiotherapy are difficult as indications of each procedure are theoretically different. Indications of GK radiosurgery are limited by the need for a well-delimited, small target volume, sufficiently far from the optic chiasm $(>5 \mathrm{~mm})$, and the dose delivered to the target must take into account the secreting characteristics of the adenoma - a lower dose is needed when the only objective is to control tumour volume - compared with the dose delivered to the chiasm, when a risk of optic neuropathy exists if
$>8 \mathrm{~Gy}$. In contrast, conventional radiotherapy should be indicated in larger tumours.

\section{Conclusions}

For all types of adenoma, GK radiosurgery should be proposed in cases of small target volume sufficiently far from the optic chiasm to avoid the risk of radiation-induced optic neuropathy. In secreting pituitary adenomas, GK represents an alternative treatment in cases of unsuccessful surgery and resistance or bad tolerance to medical treatment. Ideally, tumour residue should be low-secreting. Although still a matter of debate, it seems logical to withdraw medical therapies before GK radiosurgery, not only because of a potential risk of radioprotective effects of the drugs, but perhaps more importantly in order to be able to compare hormone levels before and after treatment of medical therapies. It should be borne in mind that mean time to remission is approximately 24-36 months, thus requiring an effective medical treatment during this period. Follow-up evaluations should be performed after the withdrawal of medical treatment to be able to correctly evaluate the efficacy of the procedure. In non-secreting pituitary adenomas, GK may be proposed in recurring adenomas after incomplete surgical resection.

Thus, GK radiosurgery seems to be an effective procedure, allowing excess hormone secretion control in $40-50 \%$ of cases and tumour volume control in all cases. With probably a lower risk of hypopituitarism than conventional radiotherapy (although there has never been a headto-head comparison), it seems to be a valuable adjunctive treatment after unsuccessful surgery, as well as an alternative treatment to badly tolerated drugs or as a first-line treatment in cases of contraindications to surgery of a small tumour.
1. Casanueva FF, Molitch ME, Schlechte JA, et al., N Engl J Med, 2006;355:2558-73.

3. Asa SL, Kovacs K, Can J Neurol Sci, 1992;19:228-35.

4. Findling JW, Raff $H_{1}, J$ Clin Endocrinol Metab, 2006; 91:3746-53.

5. Thoren M, Rahn T, Guo WY, Werner S, Neurosurgery, 1991;29:663-8.

6. Sheehan JP, Jagannathan J, Pouratian N, Steiner L, Front Horm Res, 2006;34:185-205.

7. Brada M, Ajithkumar TV, Minniti G, Clin Endocrinol (Oxf), 2004:61:531-43.

8. Biermasz NR, van Dulken H, Roelfsema F, J Clin Endocrinol Metab, 2000;85:4596-4602

9. Freda PU, Wardlaw SL, Post KD, J Neurosurg, 1998; 89:353-8.

10. Swearingen B, Barker FG II, Katznelson L, et al., J Clin Endocrinol Metab, 1998;83:3419-26.

11. Shimon I, Cohen ZR, Ram Z, Hadani M, Neurosurgery, 2001;48:1239-43, discussion 1244-35.

12. Pan L, Zhang N, Wang E, et al., Stereotact Funct Neurosurg, 1998;70(Suppl. 1):119-26.

13. Lim YL, Leem W, Kim TS, et al., Stereotact Funct Neurosurg, 1998;70(Suppl. 1): 95-109.

14. Landolt AM, Haller D, Lomax N, et al., J Neurosurg, 1998;88:1002-8.

15. Hayashi M, Izawa M, Hiyama $H$, et al., Stereotact Funct Neurosurg, 1999;72(Suppl. 1):111-18.

16. Mokry M, Ramschak-Schwarzer S, Simbrunner J, et al., Stereotact Funct Neurosurg, 1999;72(Suppl. 1):88-100.

17. Inoue HK, Kohga H, Hirato M, et al., Stereotact Funct Neurosurg, 1999;72 (Suppl. 1):125-31.

18. Zhang N, Pan L, Wang EM, et al., J Neurosurg, 2000;93 (Suppl. 3):6-9.

19. Choi JY, Chang JH, Chang JW, et al., Yonsei Med I 2003:44:602-7.

20. Castinetti F, Taieb D, Kuhn JM, et al., J Clin Endocrinol Metab, 2005:90: 4483-8.

21. Pollock BE, Jacob JT, Brown PD, Nippoldt TB, J Neurosurg, 2007; 106:833-8.

22. Attanasio R, Epaminonda P, Motti E, et al., J Clin Endocrinol Metab,
2003;88:3105-12

23. Jezkova J, Marek J, Hana V, et al., Clin Endocrinol (Oxf), 2006;64:588-95.

24. Landolt AM, Haller D, Lomax N, et al., J Clin Endocrinol Metab, 2000:85:1287-9.

25. Laws ER, Sheehan JP, Sheehan JM, et al., J Neurooncol, 2004;69:257-72.

26. Atkinson $A B$, Kennedy $A$, Wiggam Ml, et al., Clin Endocrinol (Oxf), 2005;63:549-59.

27. Chee GH, Mathias DB, James RA, Kendall-Taylor P, Clin Endocrinol (Oxf), 2001;54:617-26.

28. Rees DA, Hanna FW, Davies JS, et al., Clin Endocrinol (Oxf), 2002;56:541-51.

29. Shimon I, Ram Z, Cohen ZR, Hadani M, Neurosurgery, 2002;51:57-61, discussion 61-52.

30. Utz AL, Swearingen B, Biller BM, Endocrinol Metab Clin North Am, 2005;34:459-78.

31. Patil CG, Prevedello DM, Lad SP, et al., I Clin Endocrinol Metab, 2008;93:358-62.

32. Hoybye $C$, Grenback E, Rahn T, et al., Neurosurgery, 2001:49:284-91, discussion 291-82.

33. Pollock BE, Kondziolka D, Lunsford LD, Flickinger JC, Acta Neurochir Suppl, 1994;62:33-8.

34. Izawa M, Hayashi M, Nakaya K, et al., J Neurosurg, 2000;93 (Suppl. 3):19-22.

35. Sheehan JM, Vance ML, Sheehan JP,et al., J Neurosurg, 2000;93:738-42.

36. Kobayashi T, Kida Y, Mori Y, J Neurosurg, 2002;97:422-8.

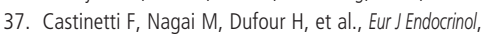
2007;156:91-8.

38. Stalla GK, Stalla J, Loeffler JP, et al., Horm Metab Res Suppl, 1987;16:31-6.

39. Kim MS, Lee SI, Sim JH, Stereotact Funct Neurosurg, 1999;72 (Suppl. 1):119-24.

40. Kim SH, Huh R, Chang JW, et al., Stereotact Funct Neurosurg, 1999;72(Suppl. 1):101-10

41. Landolt AM, Lomax N, J Neurosurg, 2000;93(Suppl. 3):14-18.

42. Pan L, Zhang N, Wang EM, et al., J Neurosurg, 2000;93
(Suppl. 3):10-13.

43. Feigl GC, Bonelli CM, Berghold A, Mokry M, J Neurosurg, 2002;97:415-21.

44. Petrovich Z, Yu C, Giannotta SL, et al., Neurosurgery, 2003:53:51-9, discussion 59-61.

45. Pollock BE, Nippoldt TB, Stafford SL, et al., I Neurosurg, 2002; 97:525-30.

46. Pamir MN, Kilic T, Belirgen M, et al., Neurosurgery, 2007; 61:270-80, discussion 280.

47. Pollock BE, Cochran J, Natt N, et al., Int J Radiat Oncol Biol Phys, 2008;70:1325-9.

48. Castinetti F, Morange I, Dufour H, et al., Pituitary, 2008; Epub ahead of print.

49. Girkin CA, Comey CH, Lunsford LD, et al., Ophthalmology, 1997;104:1634-43.

50. Stafford SL, Pollock BE, Leavitt JA, et al., Int J Radiat Oncol Biol Phys, 2003;55:1177-81.

51. Tishler RB, Loeffler JS, Lunsford LD, et al., Int J Radiat Oncol Biol Phys, 1993;27:215-21.

52. Estrada J, Boronat M, Mielgo M, et al., N Engl J Med, 1997;336:172-7.

53. Jenkins PJ, Bates P, Carson MN, et al., J Clin Endocrinol Metab, 2006;91:1239-45.

54. McCord MW, Buatti JM, Fennell EM, et al., Int I Radiat Oncol Biol Phys, 1997;39:437-44.

55. Biermasz NR, van Dulken H, Roelfsema F, J Clin Endocrinol Metab, 2000;85:2476-82.

56. Barrande G, Pittino-Lungo M, Coste J, et al., J Clin Endocrinol Metab, 2000;85:3779-85.

57. Sonino N, Zielezny M, Fava GA, et al., J Clin Endocrinol Metab, 1996;81:2647-52.

58. al-Mefty O, Kersh JE, Routh A, Smith RR, J Neurosurg, 1990;73:502-12.

59. Brada M, Ford D, Ashley S, et al., BMJ, 1992;304:1343-6.

60. Erfurth EM, Bulow B, Mikoczy Z, et al., Clin Endocrinol (Oxf), 2001;55:613-16.

61. Tsang RW, Laperriere NJ, Simpson WJ, et al., Cancer, 1993;72:2227-33. 